ARTICLE

\title{
An allosteric photoredox catalyst inspired by photosynthetic machinery
}

\author{
Alejo M. Lifschitz ${ }^{1}$, Ryan M. Young, ${ }^{1,2}$, Jose Mendez-Arroyo ${ }^{1}$, Charlotte L. Stern ${ }^{1}$, C Michael McGuirk', \\ Michael R. Wasielewski, ${ }^{1,2}$ \& Chad A. Mirkin ${ }^{1}$
}

Biological photosynthetic machinery allosterically regulate light harvesting via conformational and electronic changes at the antenna protein complexes as a response to specific chemical inputs. Fundamental limitations in current approaches to regulating inorganic light-harvesting mimics prevent their use in catalysis. Here we show that a light-harvesting antenna/reaction centre mimic can be regulated by utilizing a coordination framework incorporating antenna hemilabile ligands and assembled via a high-yielding, modular approach. As in nature, allosteric regulation is afforded by coupling the conformational changes to the disruptions in the electrochemical landscape of the framework upon recognition of specific coordinating analytes. The hemilabile ligands enable switching using remarkably mild and redox-inactive inputs, allowing one to regulate the photoredox catalytic activity of the photosynthetic mimic reversibly and in situ. Thus, we demonstrate that bioinspired regulatory mechanisms can be applied to inorganic light-harvesting arrays displaying switchable catalytic properties and with potential uses in solar energy conversion and photonic devices.

\footnotetext{
${ }^{1}$ Department of Chemistry and International Institute for Nanotechnology, Northwestern University, 2145 Sheridan Road, Evanston, Illinois 60208, USA.

${ }^{2}$ Argonne-Northwestern Solar Energy Research (ANSER) Center, Northwestern University, Evanston, Illinois 60208, USA. Correspondence and requests for materials should be addressed to C.A.M. (email: chadnano@northwestern.edu).
} 
$\Lambda$ llosteric and recognition-based control of light harvesting in natural photosynthetic systems is critical to sustaining a balanced chemical and redox environment inside cells ${ }^{1-5}$. Achieving this kind of regulation with artificial lightharvesting systems would allow one to control the production of redox and energetic feedstock from light and, subsequently, to apply chemical regulation of photosynthetic activity to systems that extend beyond the reach of biology ${ }^{6}$. Indeed, a general approach for the chemical regulation of inorganic mimics would expand their application in solar energy conversion and photonic devices, as well as enabling their use in signal amplification, catalytic switches and stimuli-responsive materials ${ }^{7-16}$. Furthermore, achieving enzyme-like regulatory properties will become useful as artificial constructs begin to be studied in the context of light-harvesting hybrid systems comprising inorganic and biological units ${ }^{17}$. While there is a rich variety of approaches for controlling light harvesting in natural systems, triggering conformational changes in antenna protein complexes as a response to specific chemical inputs (such as $\mathrm{pH}$ fluctuations) represents a common strategy that can form the basis for regulation in inorganic systems ${ }^{18-20}$. Specifically, allosterically triggered conformational changes in antenna protein complexes induce kinetically fast quenching mechanisms (for example, charge transfer and electron transfer) by changing the electronic structure of the embedded dyes or by affecting their electronic coupling with other photoactive moieties ${ }^{21-23}$.

The development of a general route for switchable inorganic mimics that can be applied to catalysis and device applications will require a novel approach which, similar to regulatory strategies in nature, allows for inducing large changes in lightharvesting efficiency using mild and selective inputs. Molecular arrays previously studied within this context have enabled remarkable self-regulation and switching of light-harvesting efficiency, yet they cannot be exploited for catalyst control given their intrinsic design limitations. For instance, the activity of light-harvesting antenna/reaction centre mimics has been regulated by appending photochromic switches that can photoisomerize into energy sinks ${ }^{24-27}$. Since the switching inputs cannot address the light-harvesting array and the switching unit independently and photoisomerization quantum yields are low, this approach is best suited to cap the overall yield of light harvesting at high light intensities rather than to create ON/OFF switches. Chemical switching via $\mathrm{pH}$ fluctuations has also been explored as a means to regulate light harvesting. Protonation can be used to tune the electronics of the lightharvesting units or to trigger the formation of energy sinks ${ }^{28,29}$. However, the need for large changes in $\mathrm{pH}$ results in switching inputs that are far more likely to affect the nature of the redox reactions catalysed by the light-harvesting array than to chemically switch the array itself, thus hampering the application of this approach in catalysis. Furthermore, the regulatory strategies mentioned above rely on quenching via the introduction of a divergent energy transfer step, which does not exhibit intrinsically faster kinetics than the light-harvesting photophysical pathways they set out to out-compete, often limiting switching ratios. Regulation of supramolecular structure in the reaction centre mimics represents a promising alternative since supramolecular switches can be operated using mild coordination inputs ${ }^{30}$ or competitive inhibitors ${ }^{31}$. While coordination chemistry has been widely used to regulate molecular logic gates, chemosensors and to manage light-driven charge separation, there are no examples in which allosteric coordination inputs are used to shuttle a photoredox catalyst between active and inactive states reversibly as observed in biological photosynthetic systems.

Against this backdrop, we describe a set of allosterically controlled light-harvesting switches that incorporate photoactive components reminiscent of photosynthetic machinery and that can be used to reversibly regulate photoredox catalytic activity in situ and reversibly ((1-3)-ImC $\mathbf{6 0}_{\mathbf{6}}$, Fig. 1). In particular, we employ an established model for a light-harvesting antenna/ reaction centre mimic composed of Bodipy, porphyrin and fullerene units, which are hereby embedded in a $\mathrm{Rh}(\mathrm{I})$ coordination complex whose interaction with allosteric

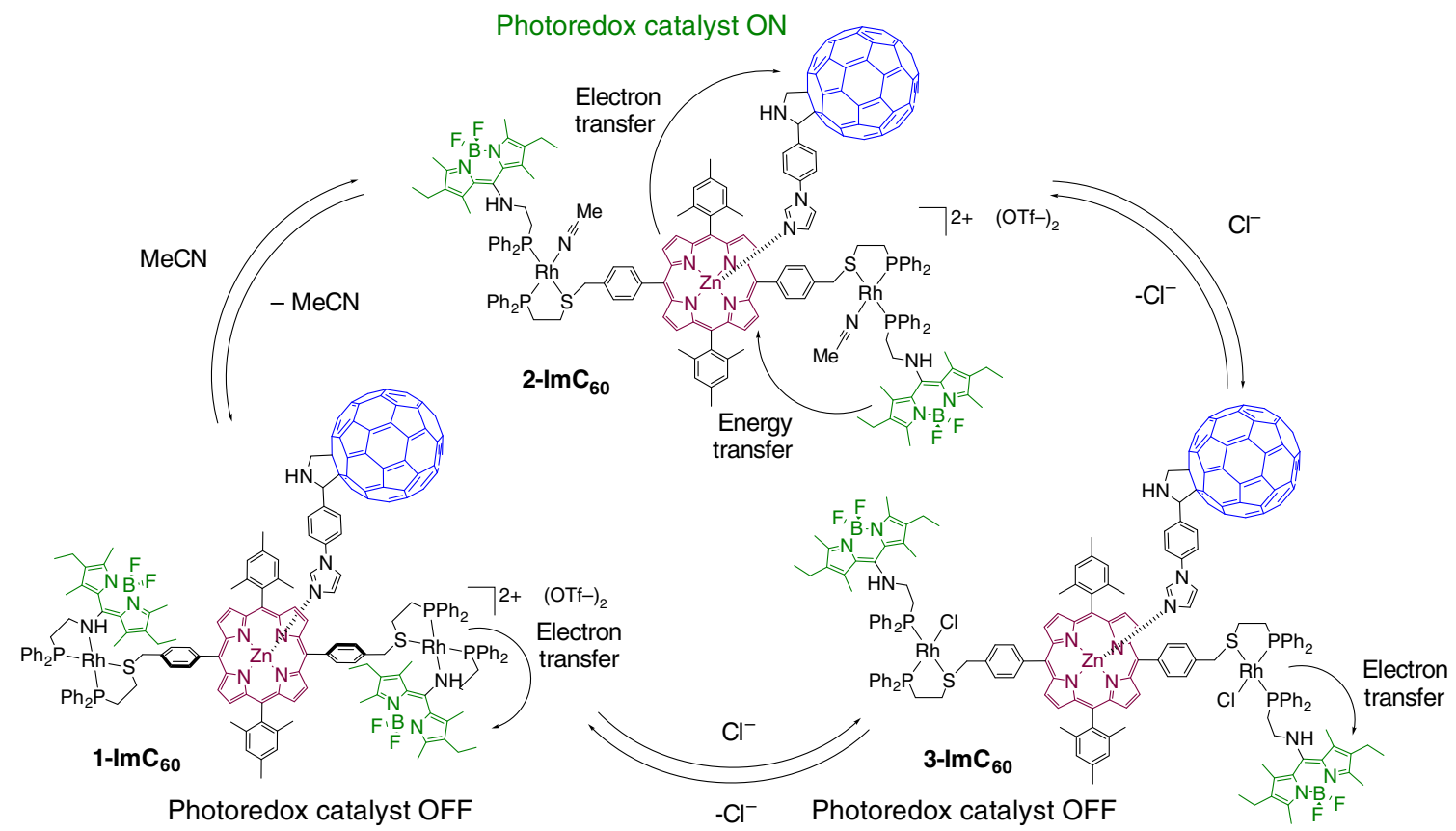

Figure 1 | Allosteric regulation of a light-harvesting antenna/reaction centre mimic. Activation of the catalytically active reaction centre mimic on the excitation of the antenna at $480 \mathrm{~nm}$ is controlled via coordination chemistry at a distal, redox-active Rh(I) centre. Light-harvesting antenna is shown in green and the reaction centre is shown in magenta and blue. 
coordinating effectors can be used to disrupt the framework's electrochemistry. This regulatory approach is based on reversibly controlling antenna hemilabile ligand coordination to an allosteric $\mathrm{Rh}(\mathrm{I})$ receptor, enabling a rare example of chemical switching via coupled electronic and structural changes ${ }^{12,32-34}$ typical of photosynthetic systems and proteins ${ }^{35-37}$. The use of a hemilabile coordination chemistry approach enables one to interconvert between active and inactive species in bulk and quantitatively using mild and redox-inactive chemical inputs that render the system compatible with a large array of redox processes. These structures are rapidly and reliably assembled via the weak-link approach (WLA) ${ }^{38}$, a synthetic strategy that exploits orthogonal coordination interactions between structural metal centres and functional hemilabile ligands. Analogous to regulation strategies in photosystem II, the switching of catalytic activity depends on regulating energy transfer from the antennae to a reaction centre mimic exploiting an intrinsically faster quenching mechanism. In particular, switch (1-3)-ImC 60 relies on utilizing coordinating effectors that control the redox potential of the antennae relative to the structural metal centres. Thus, photoinduced electron transfer $(\mathrm{PeT})^{39}$, which here arises in the sub-picosecond range ${ }^{40}$, is used to out-compete picosecond-range energy transfer from the excited antenna to the catalytically active reaction centre. While the quenched state also results in lightdriven charge separation, the redox potential of the species it is comprised of does not allow for catalytic turnover. Consequently, we are able to achieve light-harvesting switching ratios of up to 39 -fold in a bulk sample. Importantly, the activation of photoredox activity occurs selectively upon binding of allosteric effectors with the proper electron-donating ability. Thus, we demonstrate that coordination chemistry can be exploited to surmount structural, regulatory and selectivity challenges relevant to the design of light-harvesting switches, enabling their potential use in catalytic, photonic and energy conversion application devices $^{13-15,41-43}$.

\section{Results}

Design and synthesis of inactive coordination framework. In the past decade, many molecular photoactive ensembles that mimic the interactions between light-harvesting antenna and the reaction centre of photosynthetic systems ${ }^{44}$ have been built. This is typically achieved by the incorporating an antenna chromophore whose ground state can be selectively excited at a given wavelength, which triggers excitation energy transfer to an electron transfer pair wherein that energy drives the formation of a charge-separated state. In these constructs, Bodipy has often been employed as the antenna since its HOMO-LUMO (highest occupied molecular orbital and lowest unoccupied molecular orbital) gap and redox properties can be readily tuned via synthetic modifications around its core. Furthermore, Bodipy can be covalently appended to porphyrin energy acceptors, often displaying high energy transfer efficiencies ${ }^{45}$. Incorporation of an electron acceptor into Bodipy-porphyrin ensembles can be achieved via a variety of covalent or supramolecular approaches ${ }^{30}$, yet coordination of a nitrogen base-functionalized fullerene to a metallated porphyrin has proven a synthetically simpler approach that allows for PeT from the excited porphyrin to occur with high efficiency ${ }^{46-47}$. Herein, we employed a coordination-driven strategy based on the WLA to assemble a structurally switchable Bodipy-porphyrin-fullerene framework that circumvents the need for complex synthetic procedures. Towards this end, we assembled zinc porphyrin and Bodipy moieties functionalized with hemilabile coordination ligands (4 and 5, Supplementary Figs 1 and 2) around Rh(I) structural centres in a one-pot, high-yielding procedure leading to $\mathbf{1}$
(Fig. 2a). This is possible due to the WLA and the halide-induced ligand rearrangement reaction ${ }^{48}$, which serve to selectively arrange the ligands around $\mathrm{Rh}(\mathrm{I})$ yielding a heteroligated complex with porphyrin and Bodipy ligands chelated in a cis conformation. Diagnostic ${ }^{31} \mathrm{P}\left[{ }^{1} \mathrm{H}\right]$ nuclear magnetic resonance $(\mathrm{NMR})$ spectroscopy $\left(\delta: 66.8, J_{\mathrm{P}-\mathrm{P}}=38 \mathrm{~Hz}, J_{\mathrm{P}-\mathrm{Rh}}=178 \mathrm{~Hz}\right.$ and $\left.50.0, J_{\mathrm{P}-\mathrm{P}}=38 \mathrm{~Hz}, J_{\mathrm{P}-\mathrm{Rh}}=166 \mathrm{~Hz}\right)$, as well as the solid-state structure of a related compound in which the antennae are modified with a thioether spacer (X1, Supplementary Fig. 3), support this structural assignment. While the quality of the crystal structure is low $(R 1=0.14)$, the structure provides a good overall picture of the coordination mode of 1 with two bidentate hemilabile ligands coordinated to each $\mathrm{Rh}(\mathrm{I})$ centre in a cis fashion. Chelation of Bodipy ligand 5 to the charged metal centre in 1 serves to shift the antenna's oxidation potential to higher values by $180 \mathrm{mV}$ (Supplementary Figs 4-6 and Supplementary Table 1), enabling quenching of the excited Bodipy via PeT from $\mathrm{Rh}(\mathrm{I})^{40}$. This process can be observed to arise via transient absorption (TA) spectroscopy with a rate of $k_{\mathrm{PeT}}=2.0 \times 10^{12} \mathrm{~s}^{-1}$ in a model Bodipy-Rh(I) complex S1, whereas energy transfer in 1 takes place with a rate of $k_{\mathrm{EnT}}=8.3 \times 10^{10} \mathrm{~s}^{-1}$ (see Supplementary Figs 7-13). As a result, excitation of the antenna at $480 \mathrm{~nm}$ only results in minimal energy transfer to the porphyrin unit, as revealed by the fluorescence emission spectra of 1 (Fig. 2c).

Effects of allosteric effector binding. By displacing the Bodipy hemilabile ligand with a neutral allosteric effector and expanding the complex, the oxidation potential of the antenna can be shifted to more negative potentials while maintaining the oxidation potential of Rh(I) (Supplementary Fig. 5). Thus, coordination of acetonitrile in 1 to give $2\left({ }^{31} \mathrm{P}\left[{ }^{1} \mathrm{H}\right] \mathrm{NMR} \delta: 69.2, J_{\mathrm{P}-\mathrm{P}}=44 \mathrm{~Hz}, J_{\mathrm{P}-}\right.$ $\mathrm{Rh}=172 \mathrm{~Hz}$ and $25.8, J_{\mathrm{P}-\mathrm{P}}=44 \mathrm{~Hz}, J_{\mathrm{P}-\mathrm{Rh}}=160 \mathrm{~Hz}$ ) disables PeT from $\mathrm{Rh}(\mathrm{I})$ and an increase in energy transfer efficiency to the porphyrin ensues (Fig. 2c). The change in energy transfer efficiency can be approximated from changes in the lifetime of the excited antenna in $\mathbf{1}$ and $\mathbf{2}$, determined via near-infrared TA (NIR-TA) spectroscopy (Supplementary Figs 14-19), relative to previously reported $\mathrm{Rh}(\mathrm{I})$ complexes in which the zinc porphyrin unit is replaced by a benzyl group (complexes $\mathbf{S 1}$ and $\mathbf{S 2}$, see Supplementary Methods $)^{40}$. For example, comparison of the antenna excited state lifetimes $(\tau)$ in $\mathbf{1}$ and its model complex $\mathbf{S 1}$ allows us to approximate the energy transfer efficiency $(E)$ using the equation $E=1-\left(\tau_{1} / \tau_{\mathbf{S 1}}\right)$. When taking into account the change in absorption cross section following acetonitrile coordination (Fig. 2a), our data yield an 11-fold switching ratio (Supplementary Table 2). This value is particularly remarkable given the strong distance dependence of energy transfer ${ }^{49}$, suggesting that modulating PeT serves to enhance energy transfer even as the components are spatially further apart.

While energy transfer is enhanced via coordination of a neutral acetonitrile effector to $\mathbf{1}$, the incorporation of anionic chloride effectors has the opposite effect. Indeed, the formation of $\mathbf{3}$ $\left({ }^{31} \mathrm{P}\left[{ }^{1} \mathrm{H}\right]\right.$ NMR $\delta: 71.4, \mathrm{~J}_{\mathrm{P}-\mathrm{P}}=40 \mathrm{~Hz}, \mathrm{~J}_{\mathrm{P}-\mathrm{Rh}}=184 \mathrm{~Hz}$ and 30.8 , $\left.\mathrm{J}_{\mathrm{P}-\mathrm{P}}=40 \mathrm{~Hz}, \mathrm{~J}_{\mathrm{P}-\mathrm{Rh}}=166 \mathrm{~Hz}\right)$ via the addition of two equivalents of $\mathrm{N}(\mathrm{n}-\mathrm{Bu})_{4} \mathrm{Cl}$ to either $\mathbf{1}$ or 2 results in minimal porphyrin-based emission upon excitation of the antenna (Fig. 2c). The electrochemical basis for the substrate specificity is derived from the fact that chloride lowers the $\mathrm{Rh}(\mathrm{I})$ oxidation potential $(\Delta V=-553$ $\mathrm{mV}$ ) more than it shifts Bodipy's (Supplementary Fig. 6), thus enhancing rather than disabling the thermodynamic driving force for PeT from $\mathrm{Rh}(\mathrm{I})$ to Bodipy. By making the same approximations as above, we can estimate that the energy transfer efficiency in $\mathbf{3}$ is 8 times lower than in $\mathbf{1}$ and 39 times lower than in $\mathbf{2}$ (Supplementary Figs 20-25 and Supplementary Table 2). 
a
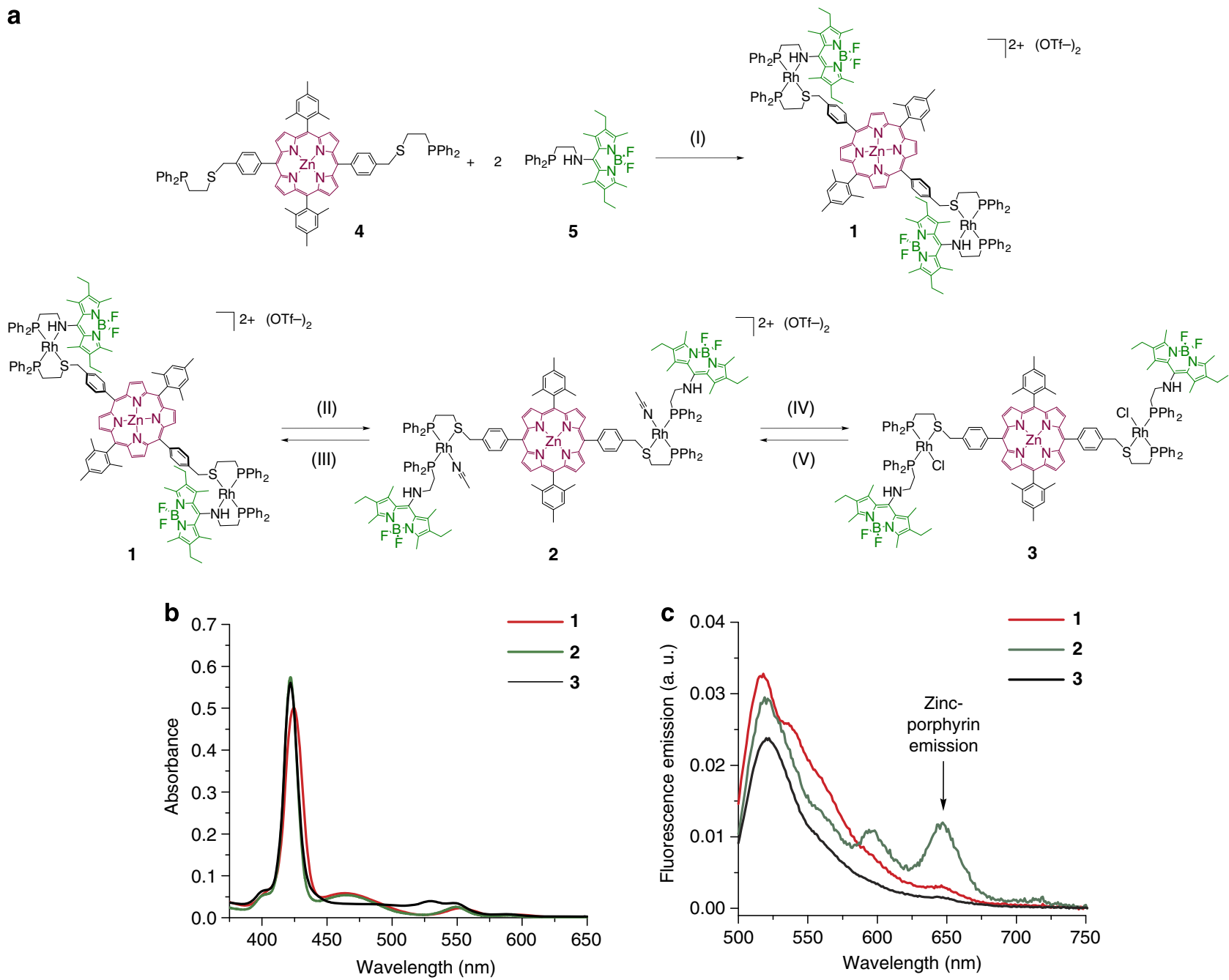

Figure 2 | Allosteric energy transfer switch operated via coordination chemistry. (a) Synthesis of WLA switch and toggling between coordination states with acetonitrile and chloride. Reaction conditions: (I) $\mathrm{Rh}_{2} \mathrm{Cl}_{2}(\mathrm{COE}), \mathrm{TI}(\mathrm{OTf}), \mathrm{CH}_{2} \mathrm{Cl}_{2}$; (II) $50 \mu \mathrm{l} \mathrm{CH} \mathrm{CN}_{2} \mathrm{CH}_{2} \mathrm{Cl}_{2}$; (III) evaporation and redissolution in $\mathrm{CH}_{2} \mathrm{Cl}_{2}$; (IV) 2 equiv. $\mathrm{N}(\mathrm{n}-\mathrm{Bu})_{4} \mathrm{Cl}, \mathrm{CH}_{2} \mathrm{Cl}_{2} ;(\mathrm{V}) 2$ equiv. TI(OTf), $\mathrm{CH}_{2} \mathrm{Cl}_{2}$. (b) Absorbance spectra and (c) fluorescence emission spectra $(\lambda$ ex $=480 \mathrm{~nm}$ ).

Importantly, the benzyl spacer in ligand $\mathbf{4}$ ensures that throughbond electronic communication between the porphyrin and the rest of the complex is reduced. Therefore, the lifetime of the excited energy acceptor is roughly constant following excitation of the antenna $(1,274 \pm 207 \mathrm{ps}$ in $1,1,126 \pm 67$ in 2 and $1,121 \pm 90 \mathrm{ps}$ in $3, \lambda=1,280 \mathrm{~nm})$ regardless of the changes in coordination mode. These values suggest that PeT from Rh(I) to Bodipy is indeed the primary contributor to the toggling of energy transfer.

Antenna-reaction centre mimic assembly. Axial coordination to the porphyrin's $\mathrm{Zn}$ (II) in 1-3 can be exploited to incorporate an imidazole-modified fullerene moiety $\left(\mathbf{I m C}_{\mathbf{6 0}}\right.$, ref. 50), thus giving (1-3)-ImC $\mathbf{6 0}_{\mathbf{6}}$. The $\mathrm{Zn}(\mathrm{II})$-imidazole association constant is within the same order of magnitude for the three complexes $\left(K_{a}=1.8 \times 10^{5} \pm 5 \%\right.$ for $1, K_{a}=1.1 \times 10^{5} \pm 18 \%$ for 2 and $K_{a}=2.7 \times 10^{5} \pm 13 \%$ for 3 , see Supplementary Figs 26-28), owing to the fact that the porphyrin ligand exhibits a structural kink introduced by the benzyl bridge. This kink renders the axial coordination site physically accessible regardless of coordination changes at the $\mathrm{Rh}(\mathrm{I})$ centre (see solid-state structure of $\mathbf{4}$ and $\mathrm{X1}$, Supplementary Figs 1 and 3). While coordination to $\mathrm{Zn}$ (II) requires an excess of $\mathbf{I m C}_{\mathbf{6 0}}$, the excess does not interfere with coordination processes at the $\mathrm{Rh}(\mathrm{I})$ centre. Indeed, ${ }^{31} \mathrm{P}\left[{ }^{1} \mathrm{H}\right] \mathrm{NMR}$ and optical spectra of (1-3)-ImC $\mathbf{C}_{\mathbf{6 0}}$ show that the coordination of hemilabile ligands $\mathbf{4}$ and $\mathbf{5}$ is not perturbed even after the addition of 40 equiv. of $\operatorname{ImC}_{\mathbf{6 0}}$ and that the framework can be interconverted reversibly and in situ between the coordination states (Supplementary Figs 29-32). Thus, a series of orthogonal coordination behaviours particular to each ligand (Bodipy, porphyrin and fullerene) allow for the straightforward assembly of a switchable light-harvesting antenna, reaction centre mimic.

Regulation of charge separation in the reaction centre mimic. The optical properties of (1-3)-ImC $\mathbf{m}_{\mathbf{6 0}}$ were studied to evaluate their ability to form catalytically active, charge-separated states. In related Bodipy-zinc porphyrin-fullerene molecular assemblies, it has been observed that the rate of electron transfer from the excited porphyrin to the fullerene is significantly faster than the rate of energy transfer from Bodipy to the porphyrin, which results in a large decrease in the porphyrin-based fluorescence quantum yield ${ }^{45,46}$. In the case of (1-3)-ImC $\mathbf{C O}_{\mathbf{6}}$, steady-state fluorescence emission spectra of the three supramolecular structures reveal that the porphyrin excited state is largely depleted following the incorporation of the fullerene moiety and excitation of the antenna (Supplementary Fig. 33). This suggests 
that, while the formation efficiency of the porphyrin excited state is different in the three coordination modes, the excited porphyrin, however much of it is produced, will undergo electron transfer to the fullerene with high efficiency in all cases. Further, when the antennae are excited in equimolar samples of (1-3)-ImC $\mathbf{F}_{\mathbf{6}}$ using the same excitation intensity, the absorbance resulting from the fullerene radical anion at $1,010 \mathrm{~nm}$, detected via NIR-TA spectroscopy, is noticeably different (Fig. 3). In particular, absorption by the fullerene anion is markedly larger in the case of 2-ImC $\mathbf{6 0}_{\mathbf{6 0}}$ (Fig. 3b) relative to both $\mathbf{1}-\mathbf{I m C}_{\mathbf{6 0}}$ and 3-ImC ${ }_{60}$ (Fig. 3a,c). This suggests that the PeT switch above, which operates simply by introducing and abstracting allosteric effectors of the proper charge, can also regulate charge separation within the central reaction centre mimic.

Allosteric control of photoredox catalytic activity. To examine whether the modulation of charge-separation efficiency translates into the regulation of photoredox activity, the reduction of methyl viologen by 1-benzyl-1,4-dihydronicotinamide was investigated in the presence of (1-3)-ImC $\mathbf{C O}_{\mathbf{0}}$ and an excitation source. This electron transfer process, which is energetically uphill in terms of the two reactants, stores about $1 \mathrm{eV}$ of the energy absorbed by the light-harvesting Bodipy antenna ${ }^{51,52}$. Indeed, in the presence of the active species 2 -ImC $\mathbf{I 0}_{\mathbf{6}}$, catalytic turnover is observed $\left(k=2.8 \times 10^{-7} \pm 0.1 \% \mathrm{~s}^{-1}\right)$, as evidenced by absorbance changes in the mixture at $630 \mathrm{~nm}$ (Fig. $4 \mathrm{a}$ and Supplementary Fig. 34), characteristic of the reduced methyl viologen species ${ }^{53}$. These bioinspired species are thus able to make use of dihydronicotinamide as a sacrificial reductant, which itself is the basis for the reduced nicotinamide adenine dinucleotide, a common redox feedstock in biology. The catalytic rate for the reduction of methyl viologen with 2-ImC $\mathbf{C O}_{\mathbf{6}}$ is similar to that observed when using a covalently appended zinc porphyrin- $\mathrm{C}_{60}$ dyad as the photoredox catalyst in which the porphyrin is directly excited ${ }^{52}$. On the other hand, the photoredox catalytic first-order rate constant becomes $k=5.7 \times 10^{-8} \pm 0.2 \% \mathrm{~s}^{-1}$ in 1-ImC $\mathbf{I m}_{\mathbf{0}}$, and catalytic turnover is indistinguishable from the background absorption for $3-\mathbf{I m C}_{\mathbf{6 0}}$ (Fig. 4a, Supplementary Figs 34-37).

The allosteric effectors employed to shuttle through (1-3)$\mathrm{ImC}_{60}$ (one drop of acetonitrile or 2 equiv. of chloride) are remarkably mild, suggesting that they could be introduced in a photoredox catalytic mixture to address the activity of the catalyst without appreciably affecting the intrinsic properties of the reactants themselves. We thus studied the allosteric regulation of the photoredox activity of (1-3)-ImC $\mathbf{I}_{\mathbf{6 0}}$ in situ. Towards this end, a $10-\mu \mathrm{M}$ solution of $\mathbf{1}-\mathrm{ImC}_{\mathbf{6 0}}$ was prepared in the presence of methyl viologen and 1-benzyl-1,4-dihydronicotinamide mixture and a number of coordination transformations were performed in the presence of an excitation source. The diminished photoredox activity displayed by $\mathbf{1}-\mathbf{I m C}_{\mathbf{6 0}}$ is significantly enhanced upon the addition of a single drop of acetonitrile to form 2 -ImC $\mathbf{I 0}_{\mathbf{0}}$, resulting in a first-order catalytic rate constant of $k=5.4 \times 10^{-7} \pm 0.1 \% \mathrm{~s}^{-1} \quad$ (Fig. $4 \mathrm{~b}$, Supplementary Fig. 38). Whereas acetonitrile cannot be abstracted without evacuating the reaction mixture, the catalyst can be deactivated and reactivated in situ via the addition and
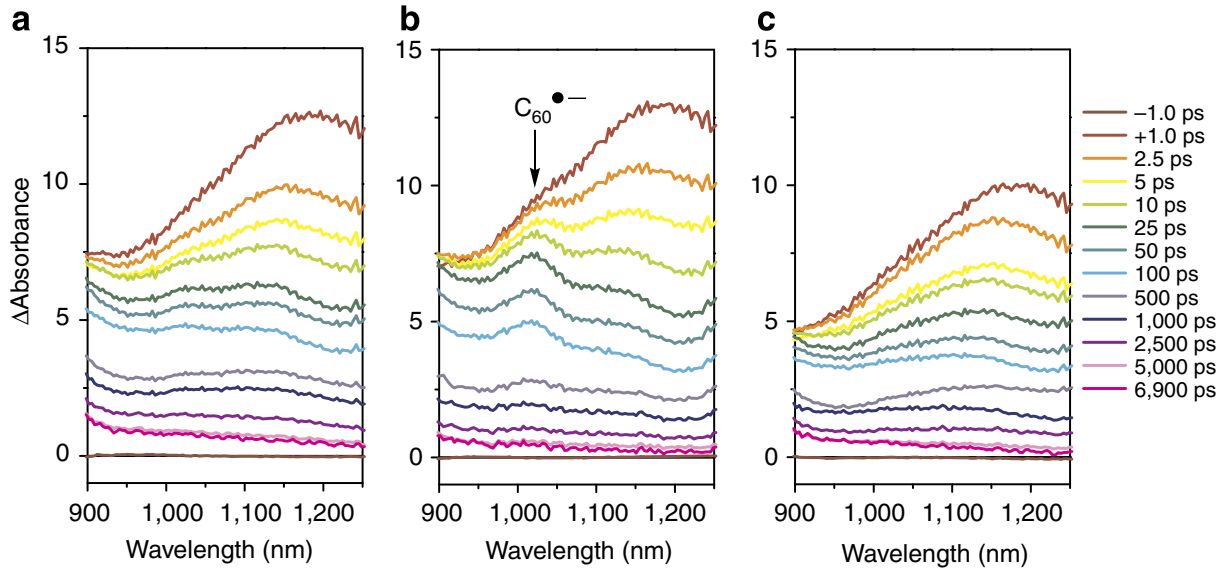

Figure 3 | NIR-TA spectra of (1-3)-ImC $\mathbf{C o}_{\mathbf{6 0}}$. Excitation of $3 \mu \mathrm{M}$ solutions of $\mathbf{1}$ (a), $\mathbf{2}$ (b) and $\mathbf{3}$ (c) with 1.1- $\mu$ J laser pulses in the presence of 10 equiv. of ImC 60 in $\mathrm{CH}_{2} \mathrm{Cl}_{2}\left(\lambda_{\mathrm{ex}}=477 \mathrm{~nm}\right)$
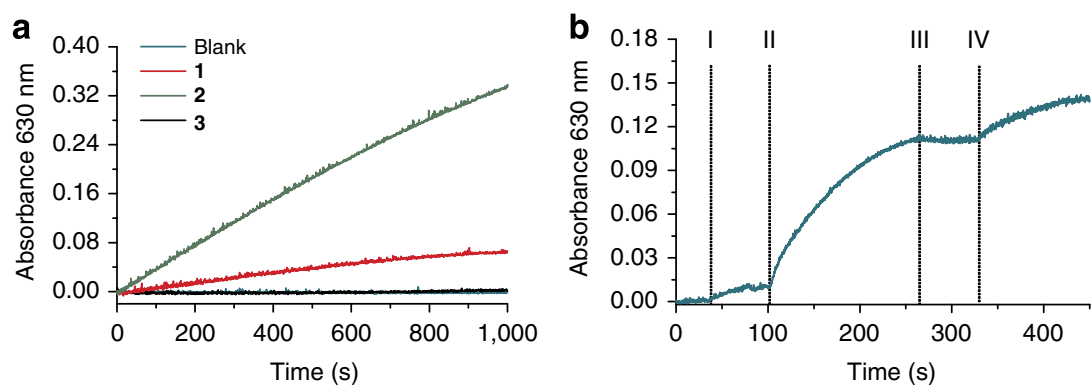

Figure 4 | Catalytic reduction of methyl viologen in the presence of (1-3)-ImC $\mathbf{6}_{\mathbf{6 0}}$. (a) Changes in the absorbance at $630 \mathrm{~nm}$ in the presence of $1 \mu \mathrm{M} \mathbf{1}, \mathbf{2}, \mathbf{3}$ or no complex (blank) with 10 equiv. of $\mathbf{I m C}_{60}\left(\lambda_{\mathrm{ex}}=480 \mathrm{~nm}, 0.8 \mathrm{~mW}\right)$ in $\mathrm{CH}_{2} \mathrm{Cl}_{2}$. (b) Changes in the absorbance at $630 \mathrm{~nm}$ in the presence of $5 \mu \mathrm{M}$ $\mathrm{CH}_{2} \mathrm{Cl}_{2}$ solution of $\mathbf{1}$ with 10 equiv. of $\mathbf{I m C}_{\mathbf{6 0}}$ on: (I) turning excitation source on ( $\boldsymbol{\lambda}_{\mathrm{ex}}=480 \mathrm{~nm}, 0.3 \mathrm{~mW}$ ), (II) addition of acetonitrile ( $1 \mathrm{drop}$ ), (III) addition of chloride (2 equiv.), and (IV) addition of TI(OTf; 6 equiv.). 
abstraction of chloride, and thus two cycles of catalyst activation can be achieved. The reactivated catalyst displays a catalytic rate constant of $k=5.2 \times 10^{-7} \pm 0.3 \% \mathrm{~s}^{-1}$, suggesting that the lightharvesting framework can be regenerated into its active state reversibly without any significant loss in catalytic activity. ${ }^{31} \mathrm{P}\left[{ }^{1} \mathrm{H}\right]$ NMR measurements of the catalytic sample revealed no degradation of the complex throughout the two cycles. However, degradation via oxidation, detected via the characteristic ${ }^{31} \mathrm{P}\left[{ }^{1} \mathrm{H}\right]$ NMR shift of alkyldiphenylphosphine oxide at $\delta: 29$ ppm, was observed upon undergoing multiple cycles of allosteric catalyst activation and deactivation.

\section{Discussion}

In the case of Photosystem II, regulation of energy transfer from light-harvesting antenna is possible since quenching via charge transfer between excited antennae occurs in the picosecond to sub-picosecond time scale ${ }^{2}$, kinetically outcompeting other decay pathways that lead to photosynthetic activity. This regulatory strategy provides the basis for switchability in the inorganic system described herein; one can chemically shuttle between two electron transfer processes, one that results in quenching and one that gives rise to catalytic activity, because the former is preceded by an inherently slower energy transfer step. Furthermore, while the charge-separated state that results from quenching the antenna can in principle reduce methyl viologen, the use of a sacrificial reductant whose oxidation potential is significantly higher than that of $\mathrm{Rh}(\mathrm{I})$ prevents its catalytic turnover in the inactive state. The multi-state switch (1-3)-ImC $\mathbf{m}_{\mathbf{6 0}}$ directly borrows the regulatory strategies seen in nature and combines them with allosteric regulation strategies by targeting a fast electron transfer process that is triggered through coupled electronic and conformational changes. As a result, (1-3)-ImC $\mathbf{m}_{\mathbf{6}}$ achieves a bulk switching ratio between the active and inactive states of up to 39-fold in terms of energy transfer efficiency, not observed by any previously developed regulatory strategy. The fact that regulation only occurs at the antenna level in (1-3)$\mathrm{ImC}_{60}$ suggests that this fundamental approach can be readily applied for controlling other light-harvesting and bioinspired photoredox systems.

In addition to demonstrating for the first time that the photoredox catalytic activity of a known light-harvesting, reaction centre mimic can be regulated in situ and reversibly, our approach to modulating electron transfer reactions allosterically also shows that coordination-based catalyst switches can be endowed with substrate selectivity. This can become a critical component of WLA catalytic switches, which have been used in the context of PCR-like inorganic substrate amplification, but which are triggered without any input selectivity. In the WLA system described herein, we have demonstrated that the activation of a central catalytic moiety in (1-3)-ImC $\mathbf{I m}_{60}$ only occurs when recognition of a targeted analyte provides the proper $\mathrm{Rh}(\mathrm{I})$ oxidation potential for light harvesting to occur. This degree of analyte selectivity will become important when applying the principles outlined herein to develop photoredox catalystbased signal amplification systems and allosterically controlled photoredox catalysts. Furthermore, (1-3)-ImC 60 may be coupled to nucleophile-releasing redox reactions ${ }^{54}$ to trigger negative feedback loops that chemically limit the efficiency of light harvesting, representing an important step towards self-regulated inorganic systems.

\section{Methods}

General methods. All reactions, transformations, characterization and catalytic experiments were performed in strictly oxygen- and water-free conditions inside a nitrogen-atmosphere glove box or in sealed containers under a stream of argon. All glassware, cuvettes and cells were oven-dried for $24 \mathrm{~h}$. Dichloromethane $\left(\mathrm{CH}_{2} \mathrm{Cl}_{2}\right)$, ether, toluene, acetonitrile and tetrahydrofuran (THF) solvents were transferred from an oxygen- and water-free solvent system (J.C. Meyer) into sealed container and purged with a stream of argon for $20 \mathrm{~min}$ before use. All the other solvents were purchased as HPLC grade, similarly purged for $20 \mathrm{~min}$ with argon and stored with activated molecular sieves. Deuterated solvents were purchased from Cambridge Isotope Laboratories and were degassed with a stream of argon before use. 5,15-Bis(mesityl)-10,20-bis(4-(chloro-methyl)phenyl)porphyrin]zinc ${ }^{55}$ $\mathbf{I m C}_{\mathbf{6 0}}{ }^{50}, \mathrm{P}, N$-Bodipy (5), P,S-benzyl (S4), model complexes $\mathbf{S 1}$ and $\mathbf{S 2}{ }^{40}$, and methlyviologen hexafluorophosphate ${ }^{56}$ were prepared from literature procedures. 1-benzyl-1,4-dihydronicotineamide was purchased from TCI chemicals and was used as received. All other chemicals were purchased from Aldrich Chemical Co. and used as received. NMR spectra were recorded on a Bruker Avance $400 \mathrm{MHz}$ (Supplementary Figs $39-62$ ). ${ }^{1} \mathrm{H}$ and ${ }^{13} \mathrm{C}\left[{ }^{1} \mathrm{H}\right] \mathrm{NMR}$ spectra were referenced to residual proton and carbon resonances in the deuterated solvents. ${ }^{13} \mathrm{C}\left[{ }^{1} \mathrm{H}\right] \mathrm{NMR}$ spectra of complexes 1-3 are not provided as WLA complexes give rise to markedly broad and featureless resonances (ref. 15). ${ }^{31} \mathrm{P}\left[{ }^{1} \mathrm{H}\right] \mathrm{NMR}$ spectra were referenced to an $85 \% \mathrm{H}_{3} \mathrm{PO}_{4}$ aqueous solution. ${ }^{19} \mathrm{~F}$ NMR spectra were referenced to a $\mathrm{CFCl}_{3}$ sample in $\mathrm{CDCl}_{3}$ solution. ${ }^{11} \mathrm{~B}\left[{ }^{1} \mathrm{H}\right]$ NMR spectra were referenced to neat $\mathrm{BF}_{3} \bullet \mathrm{OEt}_{2}$. All the chemical shifts are reported in p.p.m. High-resolution electrospray ionization (ESI) mass spectra measurements were recorded on an Agilent 6120 LC-TOF instrument in positive ion mode.

Ultraviolet-visible absorption measurements were performed in a Varian Cary 50 Bio spectrophotometer utilizing screw-cap $10-\mathrm{mm}$ cell-path quartz cuvettes (VWR). Steady-state fluorescence emission measurements were carried out in a Horiba Jovin-Yvonne Fluorolog fluorimeter and fluorescence quantum yields were derived from the comparative method using fluorescein isothiocyanate in ethanol as standard. In particular, quantum yields were calculated from the least-squares fit of the integrated fluorescence emission versus absorbance values curves comprising seven dilution samples. Cyclic voltammetry measurements were performed with an Epsilon BASi potentiostat in an air-tight cell comprising a glassy carbon working electrode, a Ag wire pseudoreference electrode and a $\mathrm{Pt}$ wire auxiliary electrode. Samples were prepared as $5 \mathrm{mM}$ solutions in $0.1 \mathrm{M} \mathrm{n}-\mathrm{Bu}_{4} \mathrm{NPF}_{6}$ in $\mathrm{CH}_{2} \mathrm{Cl}_{2}$. Scan rates of $100 \mathrm{mV} \mathrm{s}^{-1}$ were used in all measurements. All cyclic voltammetry graphs show voltages versus the ferrocene/ferrocenium couple. Titrations were performed via the addition of aliquots from a $1 \mathrm{mM}$ dichlorobenzene solution into a $1 \mu \mathrm{M}$ $\mathrm{CH}_{2} \mathrm{Cl}_{2}$ solution of $\mathrm{Rh}(\mathrm{I})$ coordination complex.

Titrations of $\mathbf{I m C}_{60}$ were studied via ultraviolet-visible spectroscopy at room temperature in a screw-cap cuvette with a total volume of $2 \mathrm{ml}$ and a constant hosts 1-3 concentration of $1 \mu \mathrm{M}$ in $\mathrm{CH}_{2} \mathrm{Cl}_{2}$. Samples were prepared in a glove box. Titrations were performed via the addition of aliquots of $1 \mathrm{mM} \mathrm{ImC}_{\mathbf{6 0}}$ solution in 1,2-dichlorobenzene into the solution of hosts 1-3. Binding affinities $\left(K_{\mathrm{a}}\right)$ were calculated by monitoring the change in absorbance at $434 \mathrm{~nm}$, corresponding to the axially coordinated porphyrin Soret band. Binding affinity was obtained by nonlinear regression analysis of the binding curves utilizing equation (1):

$$
\Delta A b s=\varepsilon \times 0.5\left([G]+[H]+\left(\frac{1}{K}\right)-\sqrt{\left(x+[H]+\left(\frac{1}{K}\right)\right)^{2}-(4 \times[H] \times[G])}\right)
$$

Photoredox catalysis. Catalytic experiments were performed in screw-cap 10-mm cell-path quartz cuvettes containing $0.1 \mathrm{mM}$ methlyviologen hexafluorophosphate and $0.1 \mathrm{mM}$ 1-benzyl-1,4-dihydronicotineamide in $\mathrm{CH}_{2} \mathrm{Cl}_{2}$. Methyl viologen was added from a concentrated methanolic solution. $\mathbf{I m C}_{\mathbf{6 0}}$ was added from a concentrated 1,2-dichlorobenzene solution. In a typical experiment, the reagents, catalyst, $\mathbf{I m C}_{\mathbf{6 0}}$ and a stir bar were loaded inside the cuvette in the dark inside a glove box. The cuvette was placed inside a ultraviolet-visible spectrophotometer and the solution was vigorously stirred with a magnetic stirrer. An encasing was built above the cuvette holder to provide a stream of argon while performing the measurements. A laser diode (PicoQuant) was placed inside the spectrophotometer perpendicular to the probe beam and excitation power was monitored regularly using a S130C slim photodiode power sensor connected to PM200 power and energy metre console (Thorlabs). The redox reaction was monitored by tracking the absorbance changes at $630 \mathrm{~nm}$, characteristic of reduced methyl viologen species. To add allosteric effectors to the reaction mixture, excitation was halted and the cuvette was taken into a glove box and then returned to the spectrophotometer.

Experimental catalytic rate constants $(k)$ were obtained by non-linear regression analysis of the kinetic curves produced by plotting the product concentration (derived from Beer's Law) versus time. Equation $[P]=\mathrm{R}_{0}\left(1-\mathrm{e}^{-\mathrm{kt}}\right)$ was fit to the experimental value using the program GraphPad using an initial starting material concentration of $0.1 \mathrm{M}$.

Time-resolved optical spectroscopy. Visible/near-infrared femtosecond TA spectroscopy was performed on an instrument that is described elsewhere ${ }^{57}$. In brief, the 827-nm fundamental output of a commercial Ti:sapphire laser system (Tsunami oscillator / Spitfire amplifier, Spectra-Physics) was frequency doubled to $414 \mathrm{~nm}(\sim 150 \mu \mathrm{J}$ per pulse). In our previous study, this was attenuated and used as the pump; here it is used to pump a seeded, two-stage, laboratory-constructed 
optical parametric amplifier. The signal output of the optical parametric amplifier was tuned to the desired wavelength then attenuated and chopped at $500 \mathrm{~Hz}$. The single-filament continuum probe was generated by focusing into the appropriate non-linear medium for the desired probe range. For visible continuum (360$800 \mathrm{~nm}), \sim 1.5 \mu \mathrm{J}$ per pulse was tightly focused into a $5-\mathrm{mm}$ cuvette containing a 1:1 mixture of $\mathrm{H}_{2} \mathrm{O}: \mathrm{D}_{2} \mathrm{O}$, while for the NIR probe $(800-1,600 \mathrm{~nm}), \sim 5 \mu \mathrm{J}$ per pulse was loosely focused into a proprietary source (Ultrafast Systems, LLC). The residual fundamental was filtered using an appropriate edge filter. The polarization of the pump beam was rotated to $54.7^{\circ}$ ('magic' angle) relative to the horizontal probe. Both pump and probe were focused to $\sim 100 \mu \mathrm{m}$ at the sample. After interaction, the transmitted probe was then coupled into an optical fibre and detected using the appropriate detector (customized Helios, Ultrafast Systems, LLC).

TA signals were fit to a convolution of a Gaussian instrument response function with the sum of a multi-exponential decay and a step function for signals extending far beyond the experimental window. Uncertainties are reported as the standard error of the fit.

X-ray crystallography. Single crystals were mounted using oil (Infineum V8512) on a glass fibre. All measurements were made on a CCD area detector with MX Optics $\mathrm{Cu} \mathrm{K} \alpha$ radiation. Data were collected using Bruker APEXII detector and processed using APEX2 from Bruker. All the structures were solved by direct methods and expanded using Fourier techniques. The non-hydrogen atoms were refined anisotropically. Hydrogen atoms were included in idealized positions, but not refined. Crystallographic information is provided in Supplementary Table 3 and Supplementary Data 1

\section{Synthesis of P,S-Bz-ZnP(mes) 2 -Bz-S,P (4). 5,15-Bis(mesityl)-10,20-Bis(4-} (chloro-methyl)phenyl)porphyrin]zinc S5 (1.50 g, $1.75 \mathrm{mmol}$ ) and P,S-TIPS S6 $(1.48 \mathrm{~g}, 3.67 \mathrm{mmol})$ were dissolved in $100 \mathrm{ml}$ of degassed THF in a Schlenk flask. $1.52 \mathrm{~g}$ of CsF were added and the mixture was left to stir in the dark at $60^{\circ} \mathrm{C}$ for $24 \mathrm{~h}$ under a nitrogen atmosphere. The reaction mixture was filtered and the solvent was evacuated. The resulting solid was redissolved in a small amount of $\mathrm{CH}_{2} \mathrm{Cl}_{2}$ and poured onto a large silica plug. The P,S-TIPS was washed with excess $\mathrm{CH}_{2} \mathrm{Cl}_{2}$ and a deep purple band was eluted with a 1:1 mixture of $\mathrm{CH}_{2} \mathrm{Cl}_{2}: \mathrm{THF}$. The product was isolated, redissolved in hot $\mathrm{CH}_{2} \mathrm{Cl}_{2}$ with a minimal amount of THF and crashed out solution by adding pentane, affording $\mathbf{4}$ as deep purple needles $\left(1.92 \mathrm{~g}, 75 \%\right.$ yield). ${ }^{1} \mathrm{H}$ NMR $\left(400.16 \mathrm{MHz}, 25^{\circ} \mathrm{C}, \mathrm{CD}_{2} \mathrm{Cl}_{2}\right): \delta 8.71\left(\mathrm{dd}, J_{\mathrm{H}}\right.$. $\mathrm{H}=6 \mathrm{~Hz}, 8 \mathrm{H}), 7.92\left(\mathrm{~d}, J_{\mathrm{H}-\mathrm{H}}=8 \mathrm{~Hz}, 4 \mathrm{H}\right), 7.37\left(\mathrm{~d}, J_{\mathrm{H}-\mathrm{H}}=8 \mathrm{~Hz}, 4 \mathrm{H}\right), 7.30(\mathrm{~s}, 4 \mathrm{H})$, $7.13(\mathrm{~m}, 12 \mathrm{H}), 6.58(\mathrm{~m}, 8 \mathrm{H}), 3.77(\mathrm{~s}, 4 \mathrm{H}), 2.63(\mathrm{~s}, 6 \mathrm{H}), 1.77(\mathrm{~m}, 16 \mathrm{H}), 1.60$ (m, $4 \mathrm{H}) .{ }^{13} \mathrm{C}\left[{ }^{1} \mathrm{H}\right]\left(100.63 \mathrm{MHz}, 25^{\circ} \mathrm{C}, \mathrm{CD}_{2} \mathrm{Cl}_{2}\right): \delta 150.3(\mathrm{~s}), 142.0(\mathrm{~s}), 140.3(\mathrm{~s})$, $139.6(\mathrm{~s}), 138.5\left(\mathrm{~d}, \mathrm{~J}_{\mathrm{C}-\mathrm{P}}=12 \mathrm{~Hz}\right), 137.9(\mathrm{~s}), 136.3(\mathrm{~s}), 135.0(\mathrm{~s}), 133.1(\mathrm{~s}), 132.7(\mathrm{~s})$, $132.4(\mathrm{~s}), 130.9(\mathrm{~s}), 129.1(\mathrm{~s}), 128.8\left(\mathrm{~d}, J_{\mathrm{C}} \mathrm{p}=5 \mathrm{~Hz}\right), 128.1(\mathrm{~s}), 127.3(\mathrm{~s}), 119.9(\mathrm{~s})$, $119.1(\mathrm{~s}), 36.6(\mathrm{~s}), 28.7\left(\mathrm{~d}, J_{\mathrm{C}-\mathrm{P}}=17 \mathrm{~Hz}\right), 27.2\left(\mathrm{~d}, J_{\mathrm{C}-\mathrm{P}}=15 \mathrm{~Hz}\right), 22.9(\mathrm{~s}), 21.6(\mathrm{~s})$. ${ }^{31} \mathrm{P}\left[{ }^{1} \mathrm{H}\right]$ NMR $\left(161.98 \mathrm{MHz}, 25^{\circ} \mathrm{C}, \mathrm{CD}_{2} \mathrm{Cl}_{2}\right): \delta-19.1$ (s). HRMS (ESI +$) \mathrm{m} / z$ calculated for $[\mathrm{M}]^{+}: 1276.3809$; found: 1276.3802

Synthesis of $\left[\mathbf{R h}_{\mathbf{2}}\left(\kappa_{\mathbf{2}}: \eta_{\mathbf{2}}: \kappa_{\mathbf{2}}-\mathbf{4}\right)\left(\kappa_{\mathbf{2}}-\mathbf{5}\right)_{\mathbf{2}}\right](\mathbf{O T f})_{\mathbf{2}}(\mathbf{1}) . \mathrm{Rh}_{2} \mathrm{Cl}_{2}(\text { cyclooctene })_{4}(3.6 \mathrm{mg}$, $0.010 \mathrm{mmol}$ ) was dissolved in $3 \mathrm{ml}$ of a 1:1 solution of $\mathrm{CH}_{2} \mathrm{Cl}_{2}: \mathrm{THF}$ and $3 \mathrm{ml}$ of $4(6.4 \mathrm{mg}, 0.005 \mathrm{mmol})$ in THF were added dropwise over the course of $5 \mathrm{~min}$. Immediately afterwards, $3(5.3 \mathrm{mg}, 0.010 \mathrm{mmol})$ dissolved in $3 \mathrm{ml}$ of THF was added dropwise. The solution was sonicated for $10 \mathrm{~min}$ and was stirred for $3 \mathrm{~h}$. The solution was concentrated to about 1 and $4 \mathrm{ml}$ of $\mathrm{CH}_{2} \mathrm{Cl}_{2}$ were added. $\mathrm{Tl}(\mathrm{OTf} ; 3.6 \mathrm{mg}, 0.010 \mathrm{mmol}$ ) was added and the mixture was stirred for $1 \mathrm{~h}$ and filtrated through a pad of Celite. The product was recrystallized from a $\mathrm{CH}_{2} \mathrm{Cl}_{2} /$ pentane solution twice, yielding 1 as a dark red solid (in situ $\left.{ }^{31} \mathrm{P}\left[{ }^{1} \mathrm{H}\right]\right\}$ NMR yields $=90-95 \%$, isolated yield $12.1 \mathrm{mg}, 85 \%) .{ }^{1} \mathrm{H}$ NMR $\left(400.16 \mathrm{MHz}, 25^{\circ} \mathrm{C}\right.$, $\left.\mathrm{CD}_{2} \mathrm{Cl}_{2}\right): \delta 7.61\left(\mathrm{~d}, J_{\mathrm{H}-\mathrm{H}}=4 \mathrm{~Hz}, 2 \mathrm{H}\right), 7.45-7.15(\mathrm{~m}, 15 \mathrm{H}), 7.12-7.00(\mathrm{~m}, 8 \mathrm{H}), 5.90$ $(\mathrm{m}, 1 \mathrm{H}), 4.26(\mathrm{~s}, 2 \mathrm{H}), 3.91(\mathrm{~m}, 2 \mathrm{H}), 2.53(\mathrm{~m}, 2 \mathrm{H}), 2.38(\mathrm{~m}, 10 \mathrm{H}), 2.20(\mathrm{~s}, 6 \mathrm{H})$, $2.12-1.95(\mathrm{~m}, 4 \mathrm{H}), 1.02\left(\mathrm{t}, J_{\mathrm{H}-\mathrm{H}}=8 \mathrm{~Hz}, 6 \mathrm{H}\right) .{ }^{31} \mathrm{P}\left[{ }^{1} \mathrm{H}\right] \mathrm{NMR}\left(161.98 \mathrm{MHz}, 25^{\circ} \mathrm{C}\right.$, $\left.\mathrm{CD}_{2} \mathrm{Cl}_{2}\right): \delta 66.8\left(\mathrm{dd}, J_{\mathrm{P}-\mathrm{P}}=38 \mathrm{~Hz}, J_{\mathrm{P}-\mathrm{Rh}}=178 \mathrm{~Hz}, 2 \mathrm{P}\right), 50.0\left(\mathrm{dd}, J_{\mathrm{P}-\mathrm{P}}=38 \mathrm{~Hz}\right.$, $\left.J_{\mathrm{P}-\mathrm{Rh}}=166 \mathrm{~Hz}, 2 \mathrm{P}\right) .{ }^{19} \mathrm{~F}$ NMR $\left(376.49 \mathrm{MHz}, 25^{\circ} \mathrm{C}, \mathrm{CD}_{2} \mathrm{Cl}_{2}\right): \delta-79.4(\mathrm{~s}, 6 \mathrm{~F})$,

$-145.6(\mathrm{~m}, 4 \mathrm{~F}) .{ }^{11} \mathrm{~B}\left[{ }^{1} \mathrm{H}\right] \mathrm{NMR}\left(128.38 \mathrm{MHz}, 25^{\circ} \mathrm{C}, \mathrm{CD}_{2} \mathrm{Cl}_{2}\right): \delta 0.09\left(\mathrm{t}, J_{\mathrm{B}-\mathrm{F}}=32\right.$ $\mathrm{Hz})$. HRMS $(\mathrm{ESI}+) \mathrm{m} / \mathrm{z}$ calculated for $[\mathrm{M}-2 \mathrm{OTf}]^{2+}: 1272.3746$; found: 1272.3762

\section{Synthesis of $\left[\mathrm{Rh}_{\mathbf{2}}\left(\mathrm{CH}_{3} \mathrm{CN}\right)_{2}\left(\kappa_{2}: \eta_{2}: \kappa_{\mathbf{2}}-\mathbf{4}\right)(5)_{2}\right](\mathrm{OTf})_{2}$ (2). Complex $1(5 \mathrm{mg}$} $1.8 \times 10^{-3} \mathrm{mmol}$ ) was dissolved in $1 \mathrm{ml}$ of $\mathrm{CH}_{2} \mathrm{Cl}_{2}$ and one drop of acetonitrile was added $\left({ }^{31} \mathrm{P}\left[{ }^{1} \mathrm{H}\right]\right.$ NMR yield: quantitative). ${ }^{1} \mathrm{H}$ NMR $\left(400.16 \mathrm{MHz}, 25^{\circ} \mathrm{C}\right.$ $\left.\mathrm{CD}_{2} \mathrm{Cl}_{2}\right): \delta 7.61\left(\mathrm{~d}, J_{\mathrm{H}-\mathrm{H}}=4 \mathrm{~Hz}, 2 \mathrm{H}\right), 7.45-7.15(\mathrm{~m}, 15 \mathrm{H}), 7.12-7.00(\mathrm{~m}, 8 \mathrm{H}), 5.90$ $(\mathrm{m}, 1 \mathrm{H}), 4.26(\mathrm{~s}, 2 \mathrm{H}), 3.91(\mathrm{~m}, 2 \mathrm{H}), 2.53(\mathrm{~m}, 2 \mathrm{H}), 2.38(\mathrm{~m}, 10 \mathrm{H}), 2.20(\mathrm{~s}, 6 \mathrm{H})$, $2.12-1.95(\mathrm{~m}, 4 \mathrm{H}), 1.02\left(\mathrm{t}, J_{\mathrm{H}-\mathrm{H}}=8 \mathrm{~Hz}, 6 \mathrm{H}\right) .{ }^{31} \mathrm{P}\left[{ }^{1} \mathrm{H}\right] \operatorname{NMR}\left(161.98 \mathrm{MHz}, 25^{\circ} \mathrm{C}\right.$, $\left.\mathrm{CD}_{2} \mathrm{Cl}_{2}\right): \delta 69.2\left(\mathrm{dd}, J_{\mathrm{P}-\mathrm{P}}=44 \mathrm{~Hz}, J_{\mathrm{P}-\mathrm{Rh}}=172 \mathrm{~Hz}, 2 \mathrm{P}\right), 25.8\left(\mathrm{dd}, J_{\mathrm{P}-\mathrm{P}}=44 \mathrm{~Hz}\right.$, $\left.J_{\mathrm{P}-\mathrm{Rh}}=160 \mathrm{~Hz}, 2 \mathrm{P}\right) .{ }^{19} \mathrm{~F}$ NMR $\left(376.49 \mathrm{MHz}, 25^{\circ} \mathrm{C}, \mathrm{CD}_{2} \mathrm{Cl}_{2}\right): \delta-79.0(\mathrm{~s}, 6 \mathrm{~F})$, $-145.4\left(\mathrm{q}, J_{\mathrm{F}-\mathrm{B}}=34 \mathrm{~Hz}, 4 \mathrm{~F}\right) .{ }^{11} \mathrm{~B}\left[{ }^{1} \mathrm{H}\right] \mathrm{NMR}\left(128.38 \mathrm{MHz}, 25^{\circ} \mathrm{C}, \mathrm{CD}_{2} \mathrm{Cl}_{2}\right): \delta 0.74$ $\left(\mathrm{t}, J_{\mathrm{B}-\mathrm{F}}=32 \mathrm{~Hz}\right)$. HRMS $(\mathrm{ESI}+) \mathrm{m} / \mathrm{z}$ calculated for $[\mathrm{M}-2 \mathrm{OTf}]^{2+}: 1313.3011$; found: 1313.3035
Synthesis of $\left[\mathbf{R h}_{\mathbf{2}} \mathrm{Cl}_{\mathbf{2}}\left(\boldsymbol{\kappa}_{\mathbf{2}}: \boldsymbol{\eta}_{\mathbf{2}}: \kappa_{\mathbf{2}} \mathbf{- 4 ) ( 5 )}\right)_{\mathbf{2}}\right]$ (3). Complex $\mathbf{1}\left(5 \mathrm{mg}, 1.8 \times 10^{-3} \mathrm{mmol}\right)$ was dissolved in $1 \mathrm{ml}$ of $\mathrm{CH}_{2} \mathrm{Cl}_{2}$ and tetrabutylammonium chloride was added. The product was precipitated from solution via the addition of pentane $\left({ }^{31} \mathrm{P}\left[{ }^{1} \mathrm{H}\right] \mathrm{NMR}\right.$ yield: quantitative, isolated yield $4.4 \mathrm{mg}, 96 \%) .{ }^{1} \mathrm{H}$ NMR $\left(400.16 \mathrm{MHz}, 25^{\circ} \mathrm{C}\right.$ $\left.\mathrm{CD}_{2} \mathrm{Cl}_{2}\right): \delta 7.61\left(\mathrm{~d}, J_{\mathrm{H}-\mathrm{H}}=4 \mathrm{~Hz}, 2 \mathrm{H}\right), 7.45-7.15(\mathrm{~m}, 15 \mathrm{H}), 7.12-7.00(\mathrm{~m}, 8 \mathrm{H}), 5.90$ $(\mathrm{m}, 1 \mathrm{H}), 4.26(\mathrm{~s}, 2 \mathrm{H}), 3.91(\mathrm{~m}, 2 \mathrm{H}), 2.53(\mathrm{~m}, 2 \mathrm{H}), 2.38(\mathrm{~m}, 10 \mathrm{H}), 2.20(\mathrm{~s}, 6 \mathrm{H})$, $2.12-1.95(\mathrm{~m}, 4 \mathrm{H}), 1.02\left(\mathrm{t}, J_{\mathrm{H}-\mathrm{H}}=8 \mathrm{~Hz}, 6 \mathrm{H}\right) \cdot{ }^{31} \mathrm{P}\left[{ }^{1} \mathrm{H}\right] \mathrm{NMR}\left(161.98 \mathrm{MHz}, 25^{\circ} \mathrm{C}\right.$ $\left.\mathrm{CD}_{2} \mathrm{Cl}_{2}\right): \delta 71.4\left(\mathrm{dd}, J_{\mathrm{P}-\mathrm{P}}=40 \mathrm{~Hz}, J_{\mathrm{P}-\mathrm{Rh}}=186 \mathrm{~Hz}, 2 \mathrm{P}\right), 30.8\left(\mathrm{dd}, J_{\mathrm{P}-\mathrm{P}}=40 \mathrm{~Hz}\right.$, $\left.J_{\mathrm{P}-\mathrm{Rh}}=166 \mathrm{~Hz}, 2 \mathrm{P}\right) .{ }^{19} \mathrm{~F}$ NMR $\left(376.49 \mathrm{MHz}, 25^{\circ} \mathrm{C}, \mathrm{CD}_{2} \mathrm{Cl}_{2}\right): \delta-145.4\left(\mathrm{q}, J_{\mathrm{F}}\right.$ $\left.{ }_{\mathrm{B}}=34 \mathrm{~Hz}, 2 \mathrm{~F}\right) .{ }^{11} \mathrm{~B}\left[{ }^{1} \mathrm{H}\right] \mathrm{NMR}\left(128.38 \mathrm{MHz}, 25^{\circ} \mathrm{C}, \mathrm{CD}_{2} \mathrm{Cl}_{2}\right): \delta 0.23\left(\mathrm{t}, J_{\mathrm{B}-\mathrm{F}}=33 \mathrm{~Hz}\right)$. HRMS $(\mathrm{ESI}+) \mathrm{m} / \mathrm{z}$ calculated for $[\mathrm{M}-2 \mathrm{Cl}]^{2+}: 1272.3746$; found: 1272.3760 .

\section{References}

1. Horton, P., Ruban, A. V. \& Wentworth, M. Allosteric regulation of the lightharvesting system of photosystem II. Phil. Trans. R. Soc. Lond. B 355, 1361-1370 (2000).

2. Ahn, T. K. et al. Architecture of a charge-transfer state regulating light harvesting in a plant antenna protein. Science 320, 794-797 (2008).

3. Ruban, A. V., Johnson, M. P. \& Duffy, C. D. P. The photoprotective molecular switch in the photosystem II antenna. Biochim. Biophys. Acta Bioenerg. 1817, 167-181 (2012).

4. Pascal, A. A. et al. Molecular basis of photoprotection and control of photosynthetic light-harvesting. Nature 436, 134-137 (2005).

5. Allen, J. F. \& Forsberg, J. Molecular recognition in thylakoid structure and function. Trends Plant Sci. 6, 317-326 (2001).

6. Scholes, G. D., Fleming, G. R., Olaya-Castro, A. \& van Grondelle, R. Lessons from nature about solar light harvesting. Nat. Chem. 3, 763-774 (2011).

7. Kobuke, Y. \& Ogawa, K. Porphyrin supramolecules for artificial photosynthesis and molecular photonic/electronic materials. Bull. Chem. Soc. Jpn 76, 689-708 (2003).

8. Rao, K. V., Datta, K. K., Eswaramoorthy, M. \& George, S. J. Light-harvesting hybrid assemblies. Chem. Eur. J. 18, 2184-2194 (2012).

9. Frischmann, P. D., Mahata, K. \& Wurthner, F. Powering the future of molecular artificial photosynthesis with light-harvesting metallosupramolecular dye assemblies. Chem. Soc. Rev. 42, 1847-1870 (2013).

10. Aguirre-Soto, A., Lim, C. H., Hwang, A. T., Musgrave, C. B. \& Stansbury, J. W Visible-light organic photocatalysis for latent radical-Initiated polymerization via $2 \mathrm{e} / 1 \mathrm{H}$ transfers: initiation with parallels to photosynthesis. J. Am. Chem. Soc. 136, 7418-7427 (2014).

11. McQuade, D. T., Hegedus, A. H. \& Swager, T. M. Signal amplification of a "turn-on" sensor: harvesting the light captured by a conjugated polymer. J. Am Chem. Soc. 122, 12389-12390 (2000).

12. Yoon, H. et al. A porphyrin-based molecular tweezer: guest-induced switching of forward and backward photoinduced energy transfer. J. Am. Chem. Soc. 136, 1672-1679 (2014).

13. Yoon, H. J. \& Mirkin, C. A. PCR-like cascade reactions in the context of an allosteric enzyme mimic. J. Am. Chem. Soc. 130, 11590-11591 (2008).

14. Masar, M. S. et al. Allosterically regulated supramolecular catalysis of acyl transfer reactions for signal amplification and detection of small molecules. J. Am. Chem. Soc. 129, 10149-10158 (2007).

15. Yoon, H. J., Kuwabara, J., Kim, J. H. \& Mirkin, C. A. Allosteric supramolecular triple-layer catalysts. Science 330, 66-69 (2010).

16. Hecht, D. S. et al. Bioinspired detection of light using a porphyrin-sensitized single-wall nanotube field effect transistor. Nano Lett. 6, 2031-2036 (2006).

17. Yadav, R. K. et al. A photocatalyst-enzyme coupled artificial photosynthesis system for solar energy in production of formic acid from CO2. J. Am. Chem. Soc. 134, 11455-11461 (2012).

18. Kiss, A. Z., Ruban, A. V. \& Horton, P. The PsbS protein controls the organization of the photosystem II antenna in higher plant thylakoid membranes. J. Biol. Chem. 283, 3972-3978 (2008).

19. Horton, P., Ruban, A. V. \& Walters, R. G. Regulation of light harvesting in green plants. Annu. Rev. Plant Phys. 47, 655-684 (1996).

20. Barber, J. An Explanation for the relationship between salt-induced thylakoid stacking and the chlorophyll fluorescence changes associated with changes in spillover of energy from Photosystem-II to Photosystem-I. FEBS Lett. 118, 1-10 (1980).

21. Ruban, A. V., Young, A. \& Horton, P. Modulation of chlorophyll fluorescence quenching in isolated light-harvesting complex of photosystem-II. Biochim. Biophys. Acta Bioenerg. 1186, 123-127 (1994).

22. Liu, Z. F. et al. Crystal structure of spinach major light-harvesting complex at 2.72 angstrom resolution. Nature 428, 287-292 (2004).

23. Holt, N. E. et al. Carotenoid cation formation and the regulation of photosynthetic light harvesting. Science 307, 433-436 (2005).

24. Raymo, F. M. \& Tomasulo, M. Electron and energy transfer modulation with photochromic switches. Chem. Soc. Rev. 34, 327-336 (2005).

25. Liddell, P. A., Kodis, G., Moore, A. L., Moore, T. A. \& Gust, D. Photonic switching of photoinduced electron transfer in a dithienylethene-porphyrin fullerene triad molecule. J. Am. Chem. Soc. 124, 7668-7669 (2002). 
26. Berera, R. et al. A simple artificial light-harvesting dyad as a model for excess energy dissipation in oxygenic photosynthesis. Proc. Natl Acad. Sci. 103, 5343-5348 (2006).

27. Straight, S. D. et al. Self-regulation of photoinduced electron transfer by a molecular nonlinear transducer. Nat. Nanotechnol. 3, 280-283 (2008).

28. Terazono, Y. et al. Mimicking the role of the antenna in photosynthetic photoprotection. J. Am. Chem. Soc. 133, 2916-2922 (2011).

29. Maity, D., Bhaumik, C., Karmakar, S. \& Baitalik, S. Photoinduced electron and energy transfer and $\mathrm{pH}$-induced modulation of the photophysical properties in homo- and heterobimetallic complexes of ruthenium(II) and rhodium(III) based on a heteroditopic phenanthroline-terpyridine bridge. Inorg. Chem. 52, 7933-7946 (2013).

30. Sandanayaka, A. S. et al. Electron transfer switching in supramolecular porphyrin-fullerene conjugates held by alkylammonium cation-crown ether binding. Chem. Commun. 4327-4329 (2006).

31. He, C. et al. A photoactive basket-like metal-organic tetragon worked as an enzymatic molecular flask for light driven $\mathrm{H}_{2}$ production. Chem. Commun. 49, 627-629 (2013).

32. Marchi, E. et al. Photoswitchable metal coordinating tweezers operated by light-harvesting dendrimers. J. Am. Chem. Soc. 134, 15277-15280 (2012).

33. Gilbert, M. et al. Conformational gating of charge separation in porphyrin oligomer-fullerene systems. J. Phys. Chem. C 117, 26482-26492 (2013).

34. Winters, M. U. et al. Control of electron transfer in a conjugated porphyrin dimer by selective excitation of planar and perpendicular conformers. Chem. Eur. J. 13, 7385-7394 (2007).

35. Goodey, N. M. \& Benkovic, S. J. Allosteric regulation and catalysis emerge via a common route. Nat. Chem. Biol. 4, 474-482 (2008).

36. Kremer, C. \& Lutzen, A. Artificial allosteric receptors. Chem. Eur. J. 19, 6162-6196 (2013)

37. Wiester, M. J., Ulmann, P. A. \& Mirkin, C. A. Enzyme mimics based upon supramolecular coordination chemistry. Angew. Chem. Int. Ed. 50, 114-137 (2011).

38. Gianneschi, N. C., Masar, M. S. \& Mirkin, C. A. Development of a coordination chemistry-based approach for functional supramolecular structures. Acc. Chem. Res. 38, 825-837 (2005).

39. da Silva, M. F. C. G., Trzeciak, A. M., Ziolkowski, J. J. \& Pombeiro, A. J. L. Redox potential, ligand and structural effects in rhodium(I) complexes. J. Organomet. Chem. 620, 174-181 (2001).

40. Lifschitz, A. M. et al. Chemically regulating $\mathrm{Rh}(\mathrm{I})$-Bodipy photoredox switches. Chem. Commun. 50, 6850-6852 (2014).

41. Kovbasyuk, L. \& Kramer, R. Allosteric supramolecular receptors and catalysts. Chem. Rev. 104, 3161-3187 (2004).

42. Niel, V. et al. Crystalline-state reaction with allosteric effect in spin-crossover, interpenetrated networks with magnetic and optical bistability. Angew. Chem. Int. Ed. 42, 3760-3763 (2003).

43. Lifschitz, A. M. et al. Boron-dipyrromethene-functionalized hemilabile ligands as "turn-on" fluorescent probes for coordination changes in weak-link approach complexes. Inorg. Chem. 52, 5484-5492 (2013).

44. Roszak, A. W. et al. Crystal structure of the RC-LH1 core complex from Rhodopseudomonas palustris. Science 302, 1969-1972 (2003).

45. Maligaspe, E. et al. Electronic energy harvesting multi BODIPY-zinc porphyrin dyads accommodating fullerene as photosynthetic composite of antennareaction center. Phys. Chem. Chem. Phys. 12, 7434-7444 (2010).

46. D'Souza, F. et al. Energy transfer followed by electron transfer in a supramolecular triad composed of boron dipyrrin, zinc porphyrin, and fullerene: a model for the photosynthetic antenna-reaction center complex. J. Am. Chem. Soc. 126, 7898-7907 (2004).

47. Terazono, Y. et al. Multiantenna artificial photosynthetic reaction center complex. J. Phys. Chem. B 113, 7147-7155 (2009).

48. Oliveri, C. G., Ulmann, P. A., Wiester, M. J. \& Mirkin, C. A. Heteroligated supramolecular coordination complexes formed via the halide-induced ligand rearrangement reaction. Acc. Chem. Res. 41, 1618-1629 (2008).

49. Stryer, L. \& Haugland, R. P. Energy transfer: a spectroscopic ruler. Proc. Natl Acad. Sci 58, 719-726 (1967).
50. D’Souza, F. et al. Spectroscopic, electrochemical, and photochemical studies of self-assembled via axial coordination zinc porphyrin-fulleropyrrolidine dyads. J. Phys. Chem. A 106, 3243-3252 (2002).

51. Chitta, R. et al. Donor-acceptor nanohybrids of zinc naphthalocyanine or zinc porphyrin noncovalently linked to single-wall carbon nanotubes for photoinduced electron transfer. J. Phys. Chem. C 111, 6947-6955 (2007).

52. Fukuzumi, S. et al. Uphill photooxidation of NADH analogues by hexyl viologen catalyzed by zinc porphyrin-linked fullerenes. J. Phys. Chem. A 106, 1903-1908 (2002).

53. Watanabe, T. \& Honda, K. Measurement of the extinction coefficient of the methyl viologen cation radical and the efficiency of its formation by semiconductor photocatalysis. J. Phys. Chem. 86, 2617-2619 (1982).

54. McNally, A., Prier, C. K. \& MacMillan, D. W. Discovery of an $\alpha$-amino C-H arylation reaction using the strategy of accelerated serendipity. Science 334, 1114-1117 (2011).

55. Jiang, B. W. \& Jones, W. E. Synthesis and characterization of a conjugated copolymer of poly(phenylenevinylene) containing a metalloporphyrin incorporated into the polymer backbone. Macromolecules 30, 5575-5581 (1997).

56. Bockman, T. M. \& Kochi, J. K. Isolation and oxidation reduction of methylviologen cation radicals. Novel disproportionation in charge-transfer salts by X-ray crystallography. J. Org. Chem. 55, 4127-4135 (1990).

57. Young, R. M. et al. Ultrafast Conformational Dynamics of Electron Transfer in ExBox $^{4+} \subset$ Perylene. J. Phys. Chem. A 117, 12438-12448 (2013).

\section{Acknowledgements}

This material is based on the work supported by the following awards, National Science Foundation CHE-1149314, U.S. Army W911NF-11-1-0229. J.M.-A. acknowledges a fellowship from Consejo Nacional de Ciencia y Tecnologia (CONACYT). Time-resolved spectroscopy was supported as part of the ANSER Center, an Energy Frontier Research Center funded by the U.S. Department of Energy, Office of Science, Office of Basic Energy Sciences under Award Number DE-SC0001059 (M.R.W. and R.M.Y.).

\section{Author contributions}

A.M.L. and C.A.M. developed the concept, and C.A.M. supervised and guided the research. All experiments were designed and performed by A.M.L., J.M.-A. and C.M.M. A.M.L. and R.M.Y. performed all TA spectroscopy measurements under the supervision of M.R.W. C.L.S. performed all crystallographic studies. A.M.L. and C.A.M. co-wrote the manuscript. All the authors discussed the results and commented on the manuscript during its preparation.

\section{Additional information}

Accession codes: The X-ray crystallographic coordinates for structures reported in this Article have been deposited at the Cambridge Crystallographic Data Centre (CCDC), under deposition numbers CCDC 1045099-1045101. These data can be obtained free of charge from The Cambridge Crystallographic Data Centre via www.ccdc.cam.ac.uk/ data_request/cif.

Supplementary Information accompanies this paper at http://www.nature.com/ naturecommunications

Competing financial interests: The authors declare no competing financial interests.

Reprints and permission information is available at http://npg.nature.com/ reprintsandpermissions/

How to cite this article: Lifschitz, A. M. et al. An allosteric photoredox catalyst inspired by photosynthetic machinery. Nat. Commun. 6:6541 doi: 10.1038/ncomms7541 (2015).

(c) (i) This work is licensed under a Creative Commons Attribution 4.0 c. International License. The images or other third party material in this article are included in the article's Creative Commons license, unless indicated otherwise in the credit line; if the material is not included under the Creative Commons license, users will need to obtain permission from the license holder to reproduce the material. To view a copy of this license, visit http://creativecommons.org/licenses/by/4.0/ 